\title{
Stakeholder Salience and Firm's Accountability on Sustainable Supply Chain Management Practices: A Case of MaxTech, Africa*
}

\author{
Ogoro Thomas Ombati1, Philip Hirschsohn² \\ ${ }^{1}$ Management Science, School of Business, University of Nairobi, Nairobi, Kenya \\ ${ }^{2}$ Economic and Management Science, School of Business \& Finance, University of Western Cape, Cape Town, \\ South Africa \\ Email: thomasombati@uonbi.ac.ke, phirschsohn@uwc.ac.za
}

Received 23 March 2015; accepted 27 April 2015; published 30 April 2015

Copyright (C) 2015 by authors and Scientific Research Publishing Inc.

This work is licensed under the Creative Commons Attribution International License (CC BY).

http://creativecommons.org/licenses/by/4.0/

(c) (i) Open Access

\begin{abstract}
Organizations are faced with stiff pressure from various stakeholders, a fact that has triggered management to think beyond the idea of shareholder wealth maximization. In order to achieve this, environmental and social concerns have been considered as pertinent issues in attaining sustainability. The present study aims to investigate how stakeholder salience, based on stakeholder power, legitimacy and urgency impacts on Sustainable Supply Chain Management (SSCM) practices. The study adopts a case study design, focusing on MaxTech, one of Africa's most innovative cellular firms. The study solicited data from management and selected stakeholders, including community, telecoms regulator, corporate customers, and the suppliers to represent different salience levels. The study used semi structured interview protocol to solicit data. This study was analyzed by use of content analysis. The study revealed that the more the number of attributes a stakeholder has, the more attention she is accorded and hence she has more influence on MaxTech's SSCM practices. Managers need to understand how to prioritize their stakeholders in order to effectively manage their expectations while sustaining the firm's bottom line.
\end{abstract}

\section{Keywords}

Stakeholder Salience, Sustainable Supply Chain Management Practices, Sustainability, Cellular Industry, MaxTech

\footnotetext{
${ }^{*}$ MaxTech is a pseudonym representing the actual case.
}

How to cite this paper: Ombati, O.T. and Hirschsohn, P. (2015) Stakeholder Salience and Firm's Accountability on Sustainable Supply Chain Management Practices: A Case of MaxTech, Africa. Journal of Service Science and Management, 8, 267278. http://dx.doi.org/10.4236/jssm.2015.82030 


\section{Background of the Study}

Organizations have an obligation not only to create wealth for their shareholders, but also to address wider stakeholder issues that are not necessarily of economic value. Supply chain partners for instance, customers, the community, governmental agencies and the shareholders have been concerned about the impact of issues including legislation, environmental disasters and large industrial changes on sustainable economic development [1]. The ever-changing customer requirements, competitive pressure, government policy, and technological innovations have resulted to changes in the telecomm sector.

According to the World Commission on Environment and Development [1], sustainability refers to those "practices and development that meet the needs of the current generation without compromising the ability of future generations to meet their needs." However, it is difficult to measure the needs of the future generations since it is not feasible to quantify them. WCED further argues that sustainability can be treated as an absolute condition since a country, community or company is either sustainable or not. In the contemporary business world, the term sustainability has become a chorus. Its prominence has been on the increase due to numerous drivers including demand and supply dynamics in consumption of energy, clear understanding of climatic shift issues as well as greater transparency on corporate environmental and social responsibility [2].

MaxTech Ltd has been experiencing an upward growth in terms of the sales volume in the last seven years. In contrast, over the last three years, its profitability has been steadily declining despite its growth in subscriptions. This has raised a host of questions on its sustainability. The key sustainability issues focused by MaxTech Ltd include: network stability, dynamic regulatory environment, energy security, innovation, supplier ethics and performance, ethics and values, employee environment and environmental performance [3]. Cellular industry has seen changes in technology and market structure and has led to its rapid growth due to improved use of the radio spectrum [4].

A number of studies have been carried out on stakeholder salience and sustainability in organizational supply chains. Stakeholder salience has a positive relationship with the level of accountability of a firm on its decisions [5]. Regarding the drivers of sustainability at British Aerospace, it was established that for SSCM to succeed there was a need to approach this initiative from an integrated perspective that was capable of addressing pertinent economic, environmental and social issues [6]. These studies confirmed the growing significance of a study on stakeholder salience and SSCM practices in the cellular industry. Unfortunately, there is no known study that has looked at topic in the telecomm sector in Country X in Africa. The case of MaxTech provides an opportunity to develop an in-depth analysis from a stakeholder perspective. This study will therefore bridge this gap. This study seeks to establish how stakeholder salience, based on stakeholder power, legitimacy and urgency impacts on Sustainable Supply Chain Management (SSCM) Practices. The specific objectives of the study will include: determining the stakeholder attributes such as power, legitimacy and urgency of selected stakeholders and the determinants of their salience; establishing the impact of stakeholder salience on Sustainable Supply Chain Management practices.

Long term survival and success of a firm depends on the strength of the relationship with all the other stakeholders in its system [7] [8]. In the stakeholder view, the greatest challenge is to identify the interests of stakeholders who will help in prioritizing and managing each set of stakeholder [7]. Stakeholders are not different in terms of importance and therefore managers need to prioritize them based on their power, legitimacy and urgency [7] [9]. Moreover, stakeholder salience is directly proportional to the firm accountability on its [5]. Criticality of stakeholders depends on the number of attributes: power, legitimacy and urgency possessed by the stakeholders. A stakeholder with all the three attributes combined is also considered more important than those with only one or two attributes [9]. Stakeholder power has more effect on salience, followed by urgency and legitimacy [10].

The conceptual model indicates that accountability on SSCM practices by a firm is determined by the level of stakeholder salience [5]. Stakeholder salience is the level of importance attached to a certain stakeholder based on the attributes such as power, legitimacy and urgency [10]. Figure 1 shows the constructs in this study.

Organizations have many stakeholders who have different levels of power, legitimacy and urgency which determine their salience [9]. Stakeholders are treated differently based on their importance. The attribute of a certain stakeholder influences the level of accountability of the firm [5]. The power a particular stakeholder has, the legitimacy of their concerns, and the urgency of their concerns enable them to hold the firm accountable. These arguments lead to the propositions. 


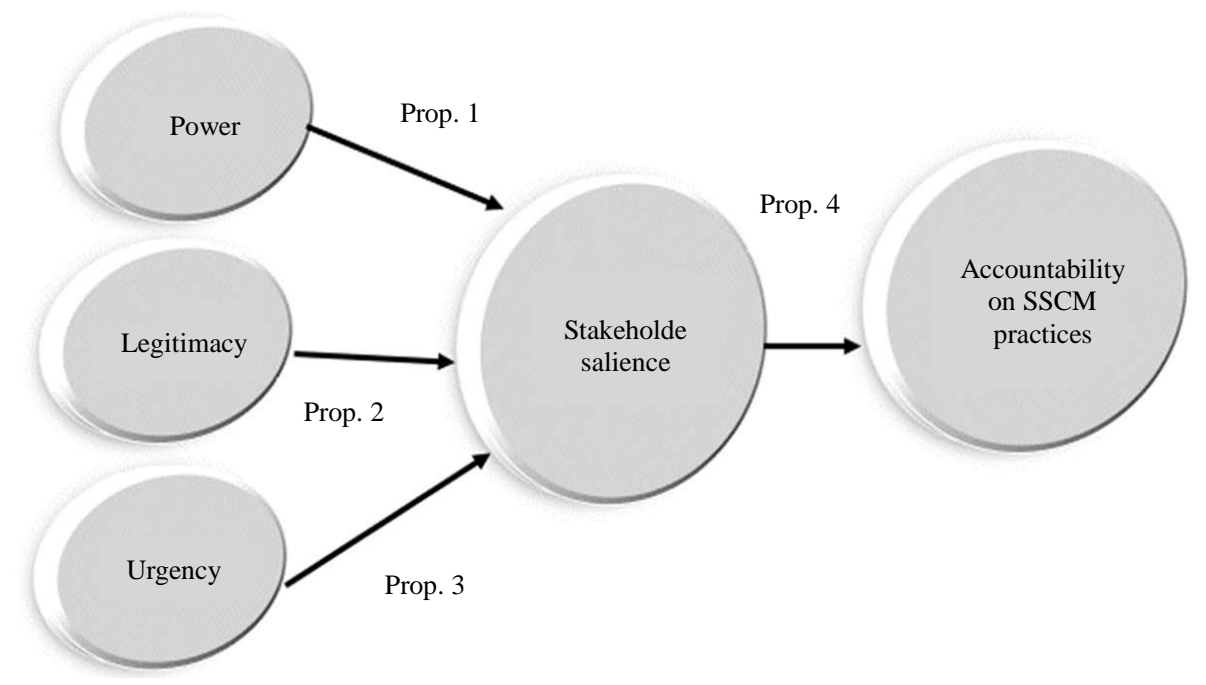

Figure 1. Conceptual model.

Proposition 1: The presence of all three of the stakeholder attributes—power, legitimacy and urgency—leads to a highest level of accountability.

Proposition 2: The presence of any two stakeholder attributes—power, legitimacy and urgency—leads to a moderate level of accountability.

Proposition 3: The presence of any one stakeholder attributes—power, legitimacy and urgency—leads to a low level of accountability.

Proposition 4: Accountability of a firm regarding their SSCM practices is influenced by stakeholder salience.

\section{Research Methodology}

The research adopted a single case study embedded with four units of analysis namely community, telecoms regulator, corporate customers and suppliers. An embedded case study involves multiple units of analysis within a case and that its adoption is based on the context and the objectives of the study [11]. An embedded case study approach was considered appropriate because of the nature of the study that required different views on stakeholder salience and SSCM practices in MaxTech.

The selection of MaxTech cellular firm in Country X was also based on its unique industry it is operating in. Cellular telephone industry uses telecommunications infrastructure that depend on scarce resources which need to be regulated by the government policy [12]. Its network is also unique in that the provision and consumption of services has a three-way channel which includes: a supplier of the infrastructure, service provider and the customer. In addition, the factors considered in the selection of this firm include: Experience of the firms in the industry, the effort with which MaxTech is addressing the economic, social and environmental issues, its accessibility and the ease with which they can avail data.

The four stakeholders namely; community, telecoms regulator, corporate customers and suppliers were selected for this study due to the different roles they play in MaxTech while addressing sustainability agenda and their varying salience levels. For MaxTech to be successful, it needs to understand each stakeholder's expectations, salience levels and the impact they creates in a firm [13]. This is because each stakeholder is managed differently by MaxTech and hence requires different categorization [9]. Data was collected from MaxTech management, community, regulators, corporate customers and suppliers were reported in that order. Interviewing multiple respondents allowed the researcher to examine various areas of the company's supply chain and act as a reality check and triangulate the data. This approach to data collection was successfully applied by Pagell and $\mathrm{Wu}[14]$.

Data was analyzed by use of content analysis. This involves movement back and forth between conceptualization, data collection, analysis and interpretation [15]. Common themes underlying stakeholder salience; power, legitimacy and urgency, accountability and SSCM practices stakeholder perspective of MaxTech cellular firm in Country X were identified. 


\section{Findings}

This section comprised of the analysis of data and the results emanating from the interview conducted with the MaxTech management, community, telecoms regulator, corporate customers and suppliers. The main objective of this study was to establish how stakeholder salience, based on stakeholder power, legitimacy and urgency impacts on the supply chain in MaxTech.

\subsection{Classification of Stakeholders Based Salience Levels}

The respondents were also required to indicate how they prioritize and identify their stakeholders. The study revealed that all stakeholders are critical to the success of MaxTech. One of the respondents stated, "All stakeholders play a key role in our organization and an action from one party has a trickle effect on the performance of the other parties. In MaxTech, we consider all stakeholders important”. Conversely, the study findings established that the management responds differently to different stakeholders depending on the number of attributes they possess. A stakeholder with all the three attributes; power, legitimacy and urgency are accorded maximum attention as opposed to those with either only one or two attributes. The respondents argued that stakeholder salience depends on the level of power, legitimacy and urgency of a specific stakeholder. The study findings indicated that the more the stakeholder attributes; power, legitimacy and urgency, the higher the level of stakeholder salience.

The results also revealed that stakeholder power, legitimacy and urgency combined have a more influence on stakeholder salience. For instance, telecoms regulator, shareholders and employees were found to possess all the three attributes and hence accorded maximum attention. These groups of stakeholders are known as definitive stakeholders. The community was found to possess power and legitimacy and hence considered dominant but later could attain definitive status by attaining urgency attribute. The customers were found to possess legitimacy and urgency attributes. The study findings also indicated that suppliers have only legitimacy attribute. Notably, some suppliers especially those who offer specialized services and are considered to be few in the market were found to possess power and legitimacy (Table 1).

The study sought to establish the factors determining the amount of stakeholder power, legitimacy and urgency. The study findings indicated that the amount of resources contributed by a certain stakeholder, level of technology and the level of investments by a stakeholder determine stakeholder power. Conversely, was established that stakeholder legitimacy is determined by the norms, values and beliefs of the firm. The legality and compliance of a stakeholder were also found to determine the legitimacy of a given stakeholder. Stakeholder urgency was found to be determined by the sensitivity of the issues addressed by stakeholders. When the stakeholders' needs require urgent attention or when they are sensitive, the management is often forced to address those needs quickly.

\subsection{Stakeholder Salience and Accountability}

The study sought the views of the four stakeholder on stakeholder salience in relation to the sustainable supply chain management practices. The community, telecoms regulator, corporate customers and suppliers were interviewed and inferences made from their responses. The findings from the interviews are discussed next.

\subsubsection{Community}

The informants were asked how their power as stakeholders is manifested in the activities carried out by MaxTech.

Table 1. Stakeholders and their attributes.

\begin{tabular}{|c|c|c|c|}
\hline \multirow{2}{*}{ Stakeholder } & \multicolumn{3}{|c|}{ Attributes } \\
\hline & Power & Legitimacy & Urgency \\
\hline Community & $\checkmark$ & $\checkmark$ & $*$ \\
\hline Regulator & $\checkmark$ & $\checkmark$ & $\checkmark$ \\
\hline Customers & $*$ & $\checkmark$ & $\checkmark$ \\
\hline Suppliers & $\checkmark$ & $\checkmark$ & $*$ \\
\hline
\end{tabular}


The research findings indicated that as stakeholders, they have both expert power and legitimacy. Regarding expert power, as community, one of the respondents indicated, "We provide the much needed services required to roll out the programs in MaxTech and so these expertise and capabilities form an important aspect of their project execution. Without our input, MaxTech cannot effectively execute its projects in our jurisdictions". This power has often been recognized, utilized and has therefore had significant impact on MaxTech activities.

The respondents said that they consider themselves legitimate to MaxTech. The study findings indicated that MaxTech finds it necessary to engage with the community early at the inception of the programs that affect them and continue to encourage participation as appropriate throughout the program's lifecycle. It makes the Company cognizant of the people that could lose business or whose livelihoods may be affected as a result of the programs. The communities continue to inform and guide them and ask for reciprocity where necessary to uplift communities. This engagement has helped to offset any potentially negative outcry or backlash that might derail their programs.

The study set out to find the source of community social responsibility network as a stakeholder. The study findings indicated that people, environment and profit are the sources of community social responsibility network. A participant stated, "We require fair and beneficial business practices toward labour and the community in which MaxTech conducts its business". The environment was also considered as a source of its social responsibility network. Sustainable environmental practices means MaxTech endeavors to benefit the natural order as much as possible or at the least minimize harm and environmental impact. For example, proper Operation Health and Safety practices, environmental friendly recharge vouchers and educating the consumers on safe disposal methods of handsets. Finally, profit was found out to be the real economic benefit enjoyed by the host society.

The research was meant to establish how fast MaxTech addresses the community concerns.

The study findings indicated that the rate at which the community concerns are addressed is based on two aspects, namely; time sensitive and critical. This depends on the nature of the issue to be addressed. Time sensitive issues were found be to addressed urgently and critical issues which are operational and health hazard are high priority and therefore are quickly addressed in a timely fashion.

The respondents thought that their concerns are addressed by MaxTech due to two reasons; the first, due to their positional power albeit low level power possessed by the community and it can terminate, derail or impede a project. Secondly, proximity to MaxTech projects is critical as it requires the community cooperation and support. As a result, it finds it necessary to cultivate positive relationships maintains them and ensures it gives back to society. The study wanted to establish the source of community time sensitivity claim as a stakeholder. The following aspects were found to be the sources of community time sensitivity claim: Environmental conservation, Operation Health and Safety (OHES) and Community Empowerment projects.

The respondents were also required to state MaxTech's level of accountability and control in regard to the firm's economic, social and environmental supply chain activities. It was clear from the study findings that the community has both low accountability over the firm's decisions.

The findings indicated that the community makes MaxTech accountable by involving them through continuous consultations, sharing development and benefits to the society. The study also found out that MaxTech also involves the community in energy management and conservation. The firm has demonstrated use of clean energy like solar power in their shelter sites and helped to distribute the same to the communities where it is operating.

The study yearned to establish what mechanisms the community has put in place to ensure that MaxTech's social and environmental activities are within the expected boundaries. The study findings indicated that the community has asked MaxTech to publish a Safety and Environment policy, accidents and hazard reports. They have ensured that MaxTech conduct public education and awareness campaigns for the community.

The study points out that it is necessary for MaxTech to cultivate positive relationships maintain the community in which it operates and make sure they give back to society. In addition, to ensure accountability, MaxTech keeps an open door for interactive dialogue, be it questioning, feedback or discussion. They are open to the community's opinions, open doors for participation and finally make sure the opinions given by the community is meaningful. Moreover, the community calls upon MaxTech to publish a Safety and Environment policy, accidents and hazard reports and impress upon the firm to conduct public education and awareness campaigns for the community. 


\subsubsection{Regulators}

The study sought to establish the level of attributes inherent in regulators with regard to the activities carried out by MaxTech. One of the significant issues was how the power of the regulators is manifested in the activities that the firm is engaged in. The findings from the study revealed that the power regulators have is purely drawn from the law that establishes the regulators. One of the respondents stated, "Our work as telecoms regulator is not to control the activities and operations of MaxTech; we only ensure that the law is followed to the latter by all the mobile phone service providers. Our power is largely drawn from the law". There are several regulators that deal with a number of issues such as the environment, provision of frequencies and competition regulation. It was clear that the power of the regulators is inclined to the Act of Parliament that outlines what they are supposed to do. The study findings indicated that the telecoms regulator has power over MaxTech. Their power is derived through regulation as enshrined by the laws of Country X. The study further revealed that the power of the regulators is therefore mainly concerned with the issue of compliancy.

The regulators have the law as their reference on what is expected of MaxTech as a telecommunication firm. The firm therefore, has no alternative other than to find ways through which compliance to the law should be obtained. The activities carried out by MaxTech regarding the environment, telecommunication or tariffs set by the company must not contravene the provisions of the law. Telecoms regulator is responsible for the issuance of license and ensures that conditions attached to it are complied with. Non compliance with the regulation leads to fines. The urgency in license renewal is critical because without it the organization will not be able to operate.

The study also set out to investigate the source of prestige or esteem of the regulators as MaxTech's stakeholders. It was revealed that the regulators do not really seek any prestige or esteem as stakeholders. The main reason for this is because their role and responsibility as stakeholders is clearly defined and outlined by the law. The law therefore becomes the main source of their perceived prestige or esteem as Safaraicom's stakeholders. The study confirms that the law is what places them in the position they hold as stakeholders and this ultimately becomes the source of their prestige and esteem. The findings also revealed that the regulators also delight in being associated with a firm that complies with the regulations that guide its operations. This is also a source of prestige and esteem for the regulators.

It was further established that the regulators have the power to withdraw some of the benefits the company enjoy. The relationship between the company and the regulators therefore takes another dimension of providers verses recipients. The providers may withdraw the benefits if at all they feel that the company is not complying with the legislation as required.

The researcher sought to establish the type of resources the regulators provide to MaxTech as stakeholders. It was clear that the regulators provide important resources that are core to the existence of the company. For instance, it was revealed that the telecoms regulator provides two important resources to the company. First, telecoms regulator allocates the spectrum frequencies and numbering resource to MaxTech. The regulator allocates the company the frequencies they use for their telecommunication services. The findings indicated that without the frequencies allocated by the regulator it will not be possible for the company to operate and provide the telecommunication services to its customers. "We have the authority to withdraw the frequency if we ascertain beyond reasonable doubt that the use of the frequency has been violated by the company". The findings revealed that provision of frequency provides a lot of power to the regulator to influence decisions made by the company. The company has to urgently address the concerns of the regulator since the consequences of doing otherwise will hit on the core of its existence.

The other resource provided by the regulator is the license to provide telecommunication services. The findings revealed that this license is issued upon the company meeting some requirements as provided for in the law. Without this license, the company will not be able to operate. It was therefore revealed that this is an important resource that the company depends on. The license provides power to the regulator to influence decisions made by the company to a very great extent. However, the regulator indicates that the fact that they provide very significant resources does not mean that they micromanage the activities of the company. It was clear from the findings that the influence is purely based on compliance to the law or withdrawal of the resources as a consequence for any violation. The regulator therefore has a strong position as far as influencing the decisions of the company is concerned.

The researcher wanted to establish how MaxTech prioritizes the concerns of the regulators as being legitimate. The study findings indicated that the concerns raised by regulators are very important and significant to be ignored by MaxTech. The regulators are very important stakeholders since they are law enforcement agents in the 
industry. The findings revealed that regulators expect the firm to give top priority to their concerns since failure to do so may attract consequences as provided for by the law. The research findings also indicated that in all the cases, the concerns of the regulators are legitimate since they originate from the law and therefore MaxTech has no alternative other than observing and treating them as legitimate.

The researcher sought to establish the source of the social responsibility network and time sensitivity claim on MaxTech's activities. It was evident from the findings of the study that the law still featured prominently as the main source of social responsibility network and time sensitivity claim. The regulators indicated that they expected MaxTech to relate to the society in which they operate according to provisions of the law. It was further clear from the study that the law requires the firm to handle various activities within specific timeframes and these must be observed. It was therefore clear that the law entirely acts as the source of the social responsibility network and time sensitivity claim for the regulators.

The study sought to investigate the urgency with which the concerns raised by the regulators are addressed by MaxTech. It was established that concerns raised by the regulators are very significant and relate to the law that regulates the operations of the firm. These concerns revealed to be very urgent and may attract adverse consequences if not addressed immediately. Some of the consequences by telecoms regulator include withdrawal of the license to operate or imposing heavy fines on the firm. The legal nature of the concerns therefore forces the firm to address the concerns of the regulators with a high degree of urgency to avoid any conflict with the law.

The findings also revealed that the speed with which the concerns of the regulators are addressed by MaxTech depends entirely on the duration the firm has been given to address any concerns raised by the regulators. In most cases, concerns raised must be addressed within a specified duration of time. MaxTech as a firm in the telecommunication industry has to comply with the time limit that it has been given to address any concerns that are raised by the regulators such as the National Environmental Authority, telecoms regulator and the Competition Authority of Country X. It was clear that failure to address these concerns within the required time as provided for in the law may attract unpleasant reaction from the regulators. It was further confirmed that in most cases, the firm has been fast enough in responding to concerns from the regulators.

The researchers wanted to ascertain the reasons why the concerns of the regulators are addressed by MaxTech. The findings revealed that there are three main reasons why the concerns of the regulators are normally addressed urgently by the firm. The first reason relates to the legitimacy of the concerns. The findings confirm that the concerns made by the regulators are by all standards based on the legal framework within which the firm should operate. This makes it possible for the concerns to be addressed since they bear issues that touch on the legality of the activities that are carried out by the firm. Illegal activities done by the firm have to be questioned and rectified by the regulators.

The second reason that makes MaxTech to address the concerns that are raised by the regulators is the issue of compliance. The study revealed that some regulators such as the telecoms regulator provide a license to operate to MaxTech and also provide the company with frequencies to use. The firm must therefore stick to the license requirements. In this case, the relationship between the regulator and the firm is purely that is based on compliance. The firm has to comply with the license requirements. A peaceful and uninterrupted operation largely depends on the ability of the company to comply with the regulations that guide their operations and relationship with other firms in the industry.

The third reason why MaxTech addresses the concerns of the regulators as stakeholders relates to the consequences of non-compliance. The law that provides for the existence and outlines the responsibilities of each of the regulators also gives them the power to take necessary action whenever the law has been violated. Some of the actions may be adverse in extreme cases such as license withdrawal. The actions may be unpleasant and may also adversely affect the business operations of the firms involved. The study therefore confirmed that MaxTech commands a sizable market share in the telecommunication industry in Country $\mathrm{X}$ may not want a situation where adverse actions have to be taken against it for failure to address concerns of regulators. The firm therefore ensures that all the concerns of the regulators are adequately addressed to avoid such extreme scenarios from taking place.

It was further confirmed that fear of the impact that may be created from some of the actions that may be taken by the regulators also forces the firm to address the concerns with a high degree of urgency. The study revealed that withdrawal of the frequencies by telecoms regulator, for instance may adversely affect customer service and revenues of the firm. This impact may be great to an extent that the company may suffer a poor public image. It was therefore evident from the findings that MaxTech addresses the concerns of the regulators to avoid 
unnecessary and unpleasant actions from the regulators. Table 2 represents the level of attributes possessed by statutory regulators.

The study further sought to ascertain what regulators do to ensure that MaxTech is accountable for its activities and whether they meet the sustainability threshold. The research results established that regulators have standards that have been set clearly by the law. It was revealed that the law has very elaborate explanations and guidelines on what firms in the telecommunications industry are supposed to do. It has set the boundaries within which the firms are supposed to operate in terms of sustainability of their activities. The findings therefore confirmed that regulators cross check the activities carried out by the company with what is outlined by the law to ensure compliance to the law.

It was also clear from the research findings that regulators hold firms in the industry responsible for all the supply chain activities that are carried out by them. Any activities that go against the law will force the regulators to demand for an explanation from the firm. The findings further revealed that the law gives the regulators authority and power to demand detailed explanation concerning any activities that are deemed as going against the provisions of the law. It was clear from the study that this kind of relationship was important to ensure that the firm is accountable for its activities and also enables the company to exercise due diligence when carrying out its activities.

The researchers sought to establish the mechanisms the regulators have put in place to ensure accountability from MaxTech's supply chain activities. It was evident from the research findings that regulators have a number of mechanisms to ensure that MaxTech is accountable to its activities. One the mechanisms as established from the study is that of periodic reporting of the activities the company is involved in. The study established that regulators require MaxTech and other firms operating in the industry to submit regular reports of all the activities they are involved in. The researchers observed that submission of these reports is not optional but an issue the company must comply with.

The other mechanism that regulators have put in place is the requirement that MaxTech and other companies in the telecommunication industry must prepare sustainability reports on an annual basis. The findings revealed that the annual sustainability reports prepared by the company outline the various activities the company is involved in and the efforts the company is making to ensure that all its activities are sustainable in the long run. The study observed that a copy of these report must be delivered to the relevant regulator in order to provide them with information concerning the activities of the company.

The study findings also confirmed that the sustainable supply chain management concerns regulators advocate for, revolve around better environmental practices such proper management of frequency spectrum in order to ensure that they are less harmful to the users and the environment, on the financial aspect the regulators require that there should be reasonable tariffs that will not lead to price wars in the industry and that the firm has to use products that will generally not be harmful to the environment and the customers. It was revealed that these sustainable supply chain practices advocated by the regulators are clearly spelt out in the law they are supposed to enforce. Their advocacy in these SSCM practices therefore mainly features what the law stipulates. It was also established from the study that quality of services and products must not be compromised by the firm in the name of SSCM practices.

\subsubsection{Corporate Customers}

The corporate customers were requested to explain how their power as stakeholders in MaxTech is manifested in the activities that are carried out by the company. The diverse responses received from the various corporate customers that were interviewed revealed that the dealers and distributors of the company have no significant

Table 2. Level of attributes possessed by statutory regulators.

\begin{tabular}{|c|c|c|c|c|}
\hline \multirow{2}{*}{ Attributes } & \multicolumn{4}{|c|}{ Level of attributes } \\
\hline & High & Moderate & Low & None \\
\hline Power & $\checkmark$ & & & \\
\hline Legitimacy & & $\checkmark$ & & \\
\hline Urgency & $\checkmark$ & & & \\
\hline
\end{tabular}


power that they can use to influence sustainable supply chain management activities within the organization. One of the respondents stated, "Nowadays MaxTech does not consult nor do they take us serious with regard to the decisions they make on matters affecting us. This is unlike the treatment we used to receive from them when MaxTech was new in the market. Currently, they just decide and tell us what they expect from us." However, it was established that the company values its dealers and distributors since they understand the role they play in ensuring that their financial, social and environmental objectives are achieved. It was further confirmed that although the corporate customers of the company did not have the power as stakeholders that could enable them dictate the sustainable supply chain activities carried out by the organization, the company does consider some of the concerns of the corporate customers as legitimate. This implies that the firm provides room for the dealers and distributors to voice their concerns that can assist in improving the sustainable supply chain management practices adopted by the company.

It was also clear from the findings that MaxTech as a company has very close contact with its corporate customers. This close contact with the dealers and distributors results from the fact that the company understands the critical role they play in the achievement of company goals and the volatile business environment that may easily make the company lose them to other competitors in the telecommunications mobile industry. The study further confirmed that although the company considers the concerns of corporate customers as being legitimate, addressing these responses entirely depends on the type of product or service that is involved in these concerns. The company has several products and services but they have various degrees of significance and this largely determines how fast a specific concern will be addressed.

The study also sought the views of the corporate customers on the source of their esteem or prestige as MaxTech stakeholders. One respondent stated, "We as customers of MaxTech, derive our esteem from the firm's outstanding performance and position as the market leader. We are happy to be associated with a company that has outstanding financial, social and environmental performance compared to other competitors in the industry”. On the source of corporate customers' social responsibility network, it was clear that the communities that are served by the company play a significant role.

The findings revealed that when the corporate customers get a forum to voice their concerns on various SSCM decisions made by MaxTech, the company tends to share more information on the various activities that it is adopting. The communication that ensues as a result of the voiced concerns provides the corporate customers with a chance to get more exposure on the SSCM activities that are being undertaken by the company.

\subsubsection{Suppliers}

The research set out to investigate supplier power and legitimacy and their role in influencing the SSCM decisions that are made by MaxTech. Several suppliers of different items were interviewed and their feedback was carefully analyzed. The following discussions relate to the findings based on the responses provided by the suppliers. The study findings indicated that MaxTech does not involve its suppliers in decision making process. One of interviewee said, "The type of relationship that exists between MaxTech and us is more less a dictatorial type of relationship. The company has total control over all the supply decisions that are made". The suppliers entirely depend on the company various decisions and they do not seem to have voice in shaping the supply decisions that are made.

It was clear from the results that the company has a structured way of handling its supply activities and this makes it difficult for suppliers to redirect them. Hence, it was established that the suppliers of the company have limited power that is manifested in the activities of the company. It was also evident that the power of a supplier is manifested in the kind of product or service the supplier offers to the company. The source of this power as was established by the study lies in the flexibility and commitment of the supplier. A supplier who is more flexible and can change according to the regulation of the company and is consistent in his commitment to the company has more power than those who have less flexibility and commitment. This implies that MaxTech takes concerns of a flexible and committed supplier more seriously and addresses them quickly than concerns of a supplier who is not flexible and lacks commitment.

The suppliers indicated that their concerns are only considered as close to legitimate. This is because most of the decisions that affect the supply activities of the company are boardroom decisions that are made and imposed on the suppliers by the company. The company uses a top down approach in dealing with its suppliers since decisions are made at the highest level of the organization and cascaded downwards to the suppliers. The suppliers have minimal say in the decision making process. However, depending on the level of flexibility and 
commitment exhibited by the supplier, the company is likely to give priority to the concerns of that particular supplier since there is power associated with flexibility and commitment. The legitimacy of the concerns voiced by the supplier will also depend on flexibility and commitment of that very supplier.

The study sought to establish from the suppliers how fast their concerns are addressed by MaxTech. It was evident from the research findings that although the relationship that exists between MaxTech and its suppliers is largely dictatorial, the company responds to supplier concerns depending on the type of service they offer to the company. Suppliers who offer critical services such as freight forwarding, logistics and other suppliers of critical items are given fast response to their concerns than those supplying items or services that are not very critical to the operations of the company. The suppliers also confirmed that the main reason why their concerns were addressed by the company is fear of losing the supplier especially those who have shown consistency in their flexibility and commitment. This is what makes the company to address the concerns with or without speed.

The suppliers were asked to explain the source of their prestige and esteem as MaxTech suppliers. The study revealed that flexibility and commitment still feature as the source of prestige and esteem of the supplier. A supplier who understands his position as being flexible towards the changes that are suggested by the company and is committed doing his part of the contract each time it is awarded can claim to have prestige and esteem. The company holds the supplier with high esteem since there is a history of consistency in flexibility and commitment that has been observed from the supplier over time. This is summarized in Table 3.

\section{Discussion of Research Findings}

The study established that MaxTech has different types of stakeholders who are treated differently depending on the attributes they have. Some stakeholders such as regulators have all the three attributes of power, legitimacy and urgency since their concerns are based on the law and are not negotiable and attract severe consequences. This confirms the position held by [5] who also established that stakeholders are treated with relative importance as far as their expectations are concerned. This position is also held by [7] [9] who established that stakeholders are not equal in terms of importance and therefore managers need to accord special attention to some of them. They further state that the criticality of stakeholders depends on the number of attributes; power, legitimacy and urgency possessed by them. This implies that a stakeholder with all the three attributes combined is considered more important than those with only one or two attributes [9].

The study findings indicated that a stakeholder with all the three attributes; power, legitimacy and urgency has a higher propensity to hold MaxTech accountable on its decisions than those stakeholders with either only one two or attributes. This finding is consistent with [5]'s work that revealed that as the number of the attributes increases, the level of salience also increases and positively impacts on the level of accountability on the firm. The study also established that all the three attributes are equally important. This revelation negates [10]'s work that concludes that power has more effect on salience, followed by urgency and legitimacy.

The study finding agrees with [7] contributions who argue that a long term survival and success of a firm

Table 3. Source of supplier power, prestige and legitimacy.

\begin{tabular}{|c|c|c|}
\hline & Source & Level \\
\hline Power & $\begin{array}{l}\text { The source of power for a supplier is } \\
\text { the level of flexibility and commitment. }\end{array}$ & $\begin{array}{l}\text { Suppliers have limited power since most decisions } \\
\text { are cascaded downwards by the company. }\end{array}$ \\
\hline Prestige and esteem & $\begin{array}{l}\text { The source of prestige and esteem of a } \\
\text { supplier is also the level of flexibility } \\
\text { and commitment. }\end{array}$ & $\begin{array}{l}\text { The degree of prestige and esteem will depend on } \\
\text { level of flexibility and commitment. Low flexibility } \\
\text { and commitment means low prestige and esteem and } \\
\text { the reverse is true. }\end{array}$ \\
\hline Legitimacy & Contractual agreement. & $\begin{array}{l}\text { The level of legitimacy also depends on the services } \\
\text { or products the supplier offers. If they are critical to } \\
\text { the organization the higher the legitimacy. }\end{array}$ \\
\hline Social responsibility network & $\begin{array}{l}\text { Source and production of goods and } \\
\text { services required by MaxTech. }\end{array}$ & $\begin{array}{l}\text { Depends on whether the sources meet acceptable } \\
\text { social standards. }\end{array}$ \\
\hline Time sensitivity & $\begin{array}{l}\text { The urgency with which the good or } \\
\text { service is required. }\end{array}$ & $\begin{array}{l}\text { Time sensitivity is high if the urgency is almost } \\
\text { immediate and low if urgency is required. }\end{array}$ \\
\hline
\end{tabular}

Source: Researcher (2014). 
depends on the strength of the relationship with all the other stakeholders in its system. In the stakeholder view, the greatest challenge is to identify the interests of stakeholders who will help in prioritizing and managing each set of stakeholder [7]. A sustained survival and growth of a firm depends on how a firm relates with its stakeholders [8].

\section{Conclusions}

Organizations are constantly competing for the existing and emerging market share. Managers are obliged to constantly evaluate their stakeholders' requirements in order to remain relevant. Regarding the stakeholders importance, it is established that stakeholders are treated differently based on what attributes they possess. Stakeholders with all the three attributes-power, legitimacy and urgency-are accorded maximum attention. Regulators for instance are found to possess all three attributes and as such their claims are addressed in a timely manner. Community has power and legitimacy. Customers do not have significant power but they are legitimate. Suppliers have no power and are treated as underdogs.

Accountability emanates from stakeholder salience. The more the attributes possessed by a stakeholder, the higher the propensity to hold MaxTech accountable for its decisions. The telecoms regulator, for instance, has the highest propensity to hold MaxTech accountable for its decisions, followed by customers then suppliers and lastly community. The study findings indicated that stakeholders held MaxTech accountable through meetings, regular communications through emails, signing of contracts and organizing symposiums.

It was evident that MaxTech stakeholders had different types of attributes. Stakeholders such as suppliers were found not to have any of the three attributes of power, influence and legitimacy. Lack of the three attributes implies that suppliers do not have any power or legitimacy in controlling the sustainable supply chain management activities adopted by MaxTech. It was further revealed that suppliers had no power to hold the firm accountable on its SSCM activities.

It emerged that customers had no significant power to influence the SSCM activities implemented by MaxTech. However, it was clear from the study findings that corporate customers had some legitimacy and urgency attributes. Some of the concerns of the corporate customers of MaxTech are legitimate and require to be addressed urgently by the company. The determinants of the legitimacy and urgency attributes possessed by corporate customers are the volume of business they offer the firm and the resources they provide to the company such as human resources. The corporate customers also provide premises that form a very significant resource necessary for the operations of the company. The resources do not, however, give the corporate customers power to influence the SSCM activities of the company. The study showed that customers expected good quality products or services, prompt feedback on their complaints, affordable products and services and user friendly products.

\section{Study Implications}

This study will contribute theoretically to the existing literature on stakeholder salience and SSCM practices. It will also enable professionals and academicians to gain a clear understanding of major practical challenges in the field. This study will also facilitate theory building which will subsequently be used as reference for future studies. It will also identify the applicability of specific features of the existing literature in the context of developing countries, hence stimulating further research.

Depicting from the relationship between stakeholder salience and SSCM practices quite a number of managerial implications arise. The managers must understand how they will be accountable in their decisions to their stakeholders. This will be achieved by properly identifying and prioritizing the stakeholders based on their salience levels. The study will help the management to understand the impact of accountability on stakeholder salience and this will ensure a systematic manipulation of the mentioned variables thus leading to the success of a firm.

The study will help managers to understand the role of supplier collaboration in the cellular firms. It points out the value of collaborating with suppliers on SSCM practices. The study encourages MaxTech management to embrace the art of partnering with it stakeholders on sustainability issues. It also presents how and what projects have been undertaken jointly by MaxTech.

The research helps cellular industry players to understand the value of stakeholder salience and its impact on SSCM practices. This aids management in cellular firms to classify various stakeholders based on their salience 
in order to improve on SSCM practices hence enhanced reputation and sustained growth of the firm.

\section{Recommendations for Future Research}

The trends and gaps acknowledged under this study necessitated the advancement of a cogent schema to guide future research on stakeholder salience and SSCM. This study focused on stakeholder salience and SSCM practices in the cellular industry, MaxTech as a case study. The findings of this study provide useful insights for future study. The researcher suggests the following studies to be conducted:

A study should be done on stakeholder salience, SSCM practices and TBL performance outcomes in the cellular industry in a given county. This study should also expand the list of the stakeholders. This will help the researcher to mitigate the limitations mentioned in this study.

There is also need for further study on stakeholder salience, SSCM practices and TBL performance outcomes in the food sector in Africa. A study on SSCM practices and TBL performance outcomes in the manufacturing industry in a certain country also ought to be done.

\section{References}

[1] WCED (1987) Our Common Future. World Commission on Environment and Development. Oxford University Press, Oxford.

[2] Carter, C.R. and Easton, P.L. (2011) Sustainable Supply Chain Management: Evolution and Future Directions. International Journal of Physical Distribution \& Logistics Management, 41, 46-62. http://dx.doi.org/10.1108/09600031111101420

[3] MaxTech Sustainability Report (2014) Sustainability Strategy.

[4] Hrovatin, N., Basle, R., Cibic, D. and Švigelj, M. (2005) The Development of Broadband in Slovenia: Why Is It Lagging behind? 16th European Regional Conference, Porto.

[5] Parmigiani, A., Klassen, R. and Russo, M. (2011) Efficiency Meets Accountability: Performance Implications of Supply Chain Configuration, Control, and Capabilities. Journal of Operations Management, 29, 212-223.

http://dx.doi.org/10.1016/j.jom.2011.01.001

[6] Gopalakrishnan, K., Yusuf, Y.Y., Musa, A., Abubakar, T. and Ambursa, H.M. (2012) Sustainable Supply Chain Management: A Case Study of British Aerospace (BAe) Systems. International Journal of Production Economics, 140, 193-203. http://dx.doi.org/10.1016/j.ijpe.2012.01.003

[7] Post, J., Preston, L. and Sachs, S. (2002) Managing the Extended Enterprise: The New Stakeholder View. California Management Review, 45, 6. http://dx.doi.org/10.2307/41166151

[8] Donald, T. and Preston, L. (1995) The Stakeholder Theory of the Corporation: Concepts, Evidence and Implications. Academy of Management Review, 20, 66-67. http://dx.doi.org/10.2307/258887

[9] Mitchell, K., Agle, R. and Wood, D. (1997) Towards a Theory of Stakeholder Identification and Salience: Defining the Principle of Who and What Really Counts. Academy of Management Review, 22, 853-886. http://dx.doi.org/10.2307/259247

[10] Parent, M.M. and Deephouse, D.L. (2007) A Case Study of Stakeholder Identification and Prioritization by Managers. Journal of Business Ethics, 75, 1-23. http://dx.doi.org/10.1007/s10551-007-9533-y

[11] Yin, R.K. (2003) Case Study Research: Design and Methods. 3rd Edition, Sage, Thousand Oaks.

[12] Fomin, V.V. (2001) The Role of Standards in Sustainable Development of Cellular Mobile Communications. Knowledge, Technology \& Policy, 14, 55-70. http://dx.doi.org/10.1007/s12130-001-1016-3

[13] Isaksson, R., Johansson, P. and Fischer, K. (2010) Detecting Supply Chain Innovation Potential for Sustainable Development. Journal of Business Ethics, 97, 425-442. http://dx.doi.org/10.1007/s10551-010-0516-Z

[14] Pagell, M. and Wu, Z. (2010) Balancing Priorities: Decision-Making in Sustainable Supply Chain Management. Journal of Operations Management, 29, 577-590.

[15] Bryman, A. and Bell, E. (2007) Business Research Methods. 